team with ideological axes to grind and covert disciplinary rivalries. With a consultant who is prepared to devote time to share in and maintain important structural procedures and to offer teaching and supervision to the team members a multidisciplinary team can undoubtedly add to patient care. Make no mistake, this is no easy option.

\section{Wilton Unit,}

Prestwich Hospital,
Manchester M25 7BI

SIR,-As a multidisciplinary team we wish to give our view of multidisciplinary teamwork and what it may be able to offer to families who seek our help in a child guidance centre. Unlike your contributors we think there are advantages in being both a multidisciplinary and a multiservice team able to offer resources not only of different skills in social work, educational psychology, and psychiatry but also of our employing authorities. These include the help offered by social services in preventing family breakdown, material help, and day care; the education department's resources especially tailored to meet the needs of a particular child; and health resources such as psychotherapy, medication, or admission to a special children's unit.

Many of the families and children we see present problems for which the medical model is inadequate and consequently responsibility has to be shared. For example, what medical or psychiatric treatment can, on its own, resolve the frustrations and bitterness inherent in a family where one child is resented and rejected as being a stepchild? Who is the patient? The angry, near-delinquent child? The despairing and near-to-suicide mother? The father denying his resentment? Or the sibling with what appear to be psychosomatic symptoms? Only by sharing responsibility can the team offer the optimum combination of skills and resources (often in short supply) to such a family.

Of course, a medical practitioner should not delegate functions requiring medical knowledge and skill to a person who does not possess them. In a multidisciplinary team he uses them and remains responsible for those functions which require them but, for example, his knowledge and skill may be less appropriate than that of an educational psychologist when an educational placemert is being considered. It is possible for medical practitioners to make a nonsensical decision about the weltare of a child because of lack of expert knowledge in a non-medical field. True multidisciplinary team work can save all the members of the team from such mistakes because they are willing to trust each other's expertise. This trust arises only from working together much of the time in a team where all the members are acceptable to one another.

Your contributors' theme appears to be that the doctor has no authority over interdisciplinary team members, suggesting that his responsibility for medical functions supersedes all the responsibilities of the other members. In fact, the other members are not merely subject to professional disciplinary procedures but they would be acting illegally in the example your contributors give-a mental welfare officer acceding to the doctor's insistence on compulsory admission of a patient when, in his opinion, the patient is capable of understanding and agreeing to admission voluntarily.
There is much confusion about the nature of multidisciplinary teams, some of which turn out to be closely knit referral systems while others are paramedical teams. In our experience true multidisciplinary teamwork can come only with an acceptance of the quality of and the differences between team members, a willingness to trust each other's expertise, and a shared responsibility.

JEAN BEVEN Alexander Burnfield SHEILA M COKER IAN HADFIELD JENNY MADDICK

Paul Allsop

Child and Family Guidance Centre,

Winchester SO23 8AD

SIR,-The original article by Drs J Appleyard and J G Maden (17 November, p 1305), your leading article (p 1245), and the subsequent correspondence have produced a dissonance which bodes ill for that co-operative harmony that is essential in a therapeutic team.

As one who has benefited greatly in such a field-although the captaincy was never, I believe, in doubt-I do not wish to add fuel to the flames by airing a view; but I believe that an error (made more than once) ought to be exposed. Section 25 of the Mental Health Act has been quoted as though it were the alpha and omega of compulsory detention. In fact, it forms the first section of part IV of the Act, which proceeds to a further 59 sections-all concerned with compulsory admission to hospital (and guardianship). The point that needs to be made is that the advice, signature, and agreement of the mental welfare officer are quite unnecessary. The original application for admission under this section can be made by the nearest relative (defined in the Act); what is obligatory is the supporting signed statements of two medical practitioners, one of whom has been approved by a local health authority as "having special experience in the diagnosis and treatment of mental disorder."

In other words the decision for compulsory admission remains firmly in the medical court and those of us who remember trying to convince a lay JP that patient $\mathrm{X}$-in a quiet phase-was in fact as mad as a hatter are duly grateful. In practice, of course, it is better for all concerned that the mental welfare officer make the original application for admissionI can only say that in 30-odd years I have never received other than total support from my colleagues in the social services.

Chale,
Isle of Wight PO38 $2 \mathrm{HB}$

WYNFORD REES

SIR,-Andrew Darby's statements (8 December, p 1510) concerning the matter of detention of patients in hospital on a section of the Mental Health Act sound impressive, but the reality of the situation is slightly different.

It is misleading to call the application a social worker makes an "executive order." It is true that in the words of the 1959 Act it is sufficient authority to detain a patient. But, if one is being exact, it is the managers of the hospital concerned to whom application is made who detain the patient. The application is what it is called and it can be made by an unqualified person-namely, the nearest relative. It is sufficient authority only if it is "duly completed." In the words of the Act, the application is "founded" on the recommendations of two medical practitioners. As it stands at present it is their opinion that decides whether a patient "ought to be detained" (Section 25) or "should be so detained" (Section 26) against his will. (Before 1959 , of course, it was a court that decided this.)

Section 54 of the Act, which contains the words quoted by $\mathrm{Dr}$ Alan Drayson (1 December, p 1442), that a mental welfare officer (MWO) should be "satisfied... an application ought to be made," is in essence a directive to the MWO to see that the application is made responsibly. (Relatives, for whom the MWO may act "in loco parentis," have been known to have all sorts of reasons why they want a patient admitted to a mental hospital.) It has to appear to the managers of the hospital where a patient is to be detained that the application is "duly made" as well as duly completed. Was it intended that half a sentence of one supplemental section of the Act should be set against the major sections $(60,65,29,136$, and 30 in addition to 25 and 26 ), where it is clear that a social worker's signature to the application or order is not strictly necessary? Maybe it should be necessary, but it is not so at present.

With regard to effecting compulsory admission, the MWO who was an experienced nurse was usually in a position to confirm the fears relatives might have and take the necessary (sometimes very positive) action. Now a social worker may not be available, 24 -hour cover not always being provided. A decision to admit may have to be taken in his absence. When he is available it may be apparent that Laing, Ssasz, and whoever else doctors, perhaps wrongly, tend to associate with the "generic" training have significantly influenced his or her thinking. Especially when the social worker refuses to sign the application, he may be no help at all in procuring health care for a seriously and sometimes dangerously ill patient. This is not to say, of course, that a generically trained social worker now does not at times play an expert and necessary part in this particular aspect of patient care.

M G REVILL

Department of Psychiatry, London N18 1QX

\section{Appointing house surgeons}

SIR,-Mr R Hall and others (8 December, p 1507) are concerned about the system of appointment of house officers. I suspect that they are not nearly as worried as their potential housemen.

The situation they describe has arisen for the following reasons. Firstly, the increasing number of graduates is not being mirrored by a comparable increase in acceptable house posts (this is possibly why they found plenty of good candidates still available at a relatively late date for their house posts). This has resulted in third and fourth year medical students becoming involved in an undignified scramble for jobs, compounded by the apparent readiness of consultants to appoint housemen on a first-come-first-served basis. This latter practice was directly responsible for the collapse of the Yorkshire region computer-matching scheme.

Despite this, the solution lies in a properly 
run computer-matching scheme, in which the consultants do not indulge in clandestine "I'll put you first if you put me first" pacts, and in which a student who has a higher preference for'a particular post than another (who in any case will have put somebody else higher) will be given the post, regardless of whether the consultant prefers the second student. Such a system is hardly new, but is the only sensible and fair way to place a large number of people in the right jobs at the right stage of their medical education. Until such a system becomes established $\mathrm{Mr} \mathrm{Hall}$ and others should continue their present policy. Many medical students will be grateful.

DAVId STREDDER

Seacroft Hospital,

\section{Domiciliary visits by consultants}

SIR,_“Dr Primus" (1 December, p 1429) is right to criticise the domiciliary visit as a way of circumventing outpatient waiting list delays in patients who are perfectly capable of attending hospital. But he should concede that properly used, the domiciliary visit can obviate the need for hospital admission in a proportion of acutely ill patients.

With the NHS short of money it is the expensive hospital sector which should be curtailed. Hospital admission means expensive staffing, equipment, and building. Consultants time may be cheaper, especially now that a glut of well-qualified doctors is inevitable. Being available to see people at home who are acutely ill is not a misuse of a consultant's time.

The domiciliary visit fee is, of course, an inducement to consultants to make themselves available for this type of work. However, a fee is trifling compared with the costs of hospital admission. Finally, involvement in domiciliary visiting keeps consultants aware of the problems faced by family doctors and improves contact between specialists and general practitioners.

Perth Royal Infirmary,

Perth PHI 1 NX

\section{Payment for general practitioners in hospitals}

SiR,-The letter from Dr C J G Menzies (1 December, $p$ 1442) on payment for general practitioners in hospitals highlights one of the problems inherent in applying nationally negotiated agreements to every variable local situation.

Since the inception of the NHS the vast majority of general practitioner hospitals have provided a casualty service for which they received no payments. The bed fund was deemed by the DHSS to provide adequate payment for both inpatient and casualty cover A small minority in such hospitals had managed to persuade their employing authorities to make special pavments for casualty services but there were no central guidelines and most authorities refused to make ad hoc arrangements.

Circular $\mathrm{HC}(\mathrm{PC})(79) 5$ was agreed in an attempt to correct this situation. The new circular was overwhelmingly welcomed both by the Conference of Local Medical Com- mittees and by the Association of General Practitioner Hospitals. Paragraph 9, which limits the new method of payments to GP hospitals where the casualty service is staffed entirely by GPs, was inserted at the insistence of CCHMS representatives who foresaw a possible threat to accident and emergency departments in district general hospitals if the new method of GP payments were to spread beyond purely GP hospitals. Any circular regarding employment of doctors in the hospital service can be introduced only with the agreement of representatives of hospital doctors.

The situation at Harwich where an $\mathrm{SHO}$ is employed by the area health authority to help with the work in the casualty department of a GP hospital must be rare. Incidentally, there are very many GP hospitals which cope with attendance rates of new casualty patients many times greater than those at Harwich without requiring the assistance of hospital-based doctors.

Dr Menzies had already contacted the BMA for advice prior to the publication of his letter and possible solutions to the Harwich problem are being actively pursued by the GMSC and the DHSS. It is to be anticipated that other local anomalies will arise from implementation of the new circular and the GMSC will be pleased to offer advice and to help in such situations

The fact remains, however, that in over $95^{\circ}$ of GP hospitals introduction of the circular has resulted in increased payments into the medical staff funds, in many cases of the order of several hundred per cent. For rather different reasons I am inclined to agree with Dr Menzies that this is "an incredible contract," though I cannot agree that the majority of GPs working in GP hospitals are no better off as a result of its introduction.

\section{P J ENOCH} BMA House, London WCiH 9JP

\section{Out-of-hours services by medical}

laboratory scientific officers

SIR,-The national dispute between the Association of Scientific, Technical and Managerial Staffs (ASTMS) and the Department of Health has resulted in restrictions in the provision of out-of-hours emergency laboratory services in some hospitals. I am informed that at least one health board has agreed with the ASTMS arrangements, which contravene the Whitley Council regulations and which are liable to prove very expensive. While such local arrangements are intended to be temporary, and to apply only until national agreement is reached, there is danger that they may remain extant for longer than may originally have been anticipated. In some instances such agreements may have been necessary to safeguard the welfare of patients, but I understand that they have also been made, or offered, to medical laboratory scientific officers (MLSOs) working in laboratories in which the medical staff was prepared if necessary to provide an emergency service, as Professor Whitby (17 Nov, p 1296) and his colleagues are doing.

If such local arrangements become widespread and remain in force for long, they will certainly be very costly. If they contravene the Whitley Council regulations, as I believe they do, is it likely that additional central funds will be provided to meet the extra cost? If not, how is the cost to be met? In particular, will it be deducted from the budget of the hospital or laboratory incurring the costs of such agreements?

This college cannot become involved in the remuneration of laboratory staff. However, one of its major functions is to ensure the provision of a high standard of pathological services. Any reduction in the revenue available for maintaining and improving laboratory services and for upgrading standards of laboratory safety, whether due to the additional costs of emergency services or other cause, would be strongly opposed by the college. It may be that Professor Whitby was led by such considerations to oppose proposals which he believes to be in contravention of Whitley, in which case he deserves support for the stand he has taken.

Actual costs of agreements for out-of-hours work have a habit of far exceeding the estimates, as happened when UMTs were introduced as a result of industrial action by doctors. It seems appropriate to suggest that heads of pathology departments should seek reassurance from their employing authorities that the extra cost of implementing expensive local arrangements for out-of-hours work will not be deducted from the revenue of their departments, or indeed from other parts of the NHS where the loss would lead to a deterioration in patient care.

J R ANDERSON

London SW1Y $5 \mathrm{AH}$

President, Royal College of Pathologists

\section{Penis captivus has occurred}

SIR,-In reply to Dr F Kräupl Taylor's article on penis captivus (20 October, p 977), which was recently brought to my attention, there can be no doubt but that I have seen a case of this seemingly rare condition.

The year was 1947 and the case occurred when I was a houseman at the Royal Isle of Wight County Hospital. I can distinctly remember the ambulance drawing up and two young people, a honeymoon couple I believe, being carried on a single stretcher into the casualty department. An anaesthetic was given to the female and they were discharged later the same morning.

In view of the number of letters that have recently been written on this subject I rang my old friend Dr S W Wolfe, who is now in general practice in Bridgwater, and who was the other houseman at the hospital at the time. He confirmed my story, his exact words being, "I remember it well."

Brendan Musgrave

London NW4 4AY

$*_{*}^{*}$ Although the correspondence on this subject was closed we are making an exception for this one letter as it reports personal experience of a case.-ED, BMF.

\section{An interesting person}

SIR,-Minerva (1 December, p 1446) in reviewing the Graduate's Travel Guide by John Borrie of Otago University says, "Surely there must be at least one interesting person in New Zealand." There is. I am he.

Auckland, New Zealand
JOHN G MALCOMSON 